\title{
Grading Ductal Carcinoma In Situ (DCIS) of the Breast - What's Wrong with It?
}

\author{
Gábor Cserni ${ }^{1,2}$ (1) Anita Sejben ${ }^{2}$
}

Received: 4 July 2019 / Accepted: 1 October 2019 / Published online: 27 November 2019

(C) The Author(s) 2019

\begin{abstract}
Ductal carcinoma in situ of the breast is a non-obligate precursor of invasive breast cancer, and at its lower risk end might not need treatment, a hypothesis tested in several currently running randomized clinical trials. This review describes the heterogeneity of grading ductal carcinoma in situ (DCIS). First it considers differences between low and high grade DCIS, and then it looks at several grading schemes and highlights how different these are, not only in the features considered for defining a given grade but also in their wording of a given variable seen in the grade in question. Rather than being fully comprehensive, the review aims to illustrate the inconsistencies. Reproducibility studies on grading mostly suggestive of moderate agreement on DCIS differentiation are also illustrated. The need for a well structured, more uniform and widely accepted language for grading DCIS is urged to avoid misunderstanding based misclassifications and improper treatment selection.
\end{abstract}

Keywords Breast cancer - Ductal carcinoma in situ - Grade

\section{Introduction - Something Personal, to Begin with...}

The first author, among many other (about 50) participants, was asked to classify ductal carcinoma in situ (DCIS) along several features (10 "scored" variables) in a set of nearly 150 digital slides each representing a single case from a series of 353 DCIS with known outcome. This task was accepted voluntarily as the study framing this exercise has very ambitious and complex aims, which include sorting out some troubles of DCIS classification and possibly clarifying which cases could safely avoid the relatively uniform treatment of a heterogeneous disease summarized under the same name of DCIS. The study coordinated by Jelle Wesseling from the

Electronic supplementary material The online version of this article (https://doi.org/10.1007/s12253-019-00760-8) contains supplementary material, which is available to authorized users.

Gábor Cserni

cserni@freemail.hu

1 Department of Pathology, Bács-Kiskun County Teaching Hospital, Nyíri út 38, Kecskemét H-6000, Hungary

2 Department of Pathology, University of Szeged, Állomás u. 1, Szeged H-6725, Hungary
Netherlands Cancer Institute also looks at the possibility whether standard morphology is capable of sorting out, identifying these latter cases, which are likely to be overtreated with a "one size fits all" approach. So motivation, daily practice expertise (and beyond), a friendly relation with the coordinator of the study were all there to go ahead and score the cases. But then, at the first case, looking at the variables to score and the advice to follow everyone's own routine made this author uncertain. By the end of the few hours spent on grading DCIS and classifying it otherwise, the sense of chaotic set of rules or chaos from the lack of rules and the feeling of being far away from perfectness resulted in frustration. This feeling initiated the writing of this review, which tries to give an impression on how far we are from a uniform approach to DCIS.

\section{DCIS as a Precursor of Invasive Carcinomas}

Ductal carcinoma in situ (DCIS) is well accepted as a nonobligate precursor of invasive breast carcinomas. As invasive breast cancer is not a single disease, it is more than logical that its precursor cannot be one disease either. Invasive carcinomas are classified according to histological type, grade, biomarker expression, stage ... etc. Similarly, DCIS is also classified 
along several features: e.g. pattern, grade, necrosis and biomarker expression.

It is currently held that low grade (well differentiated, grade 1) invasive breast carcinomas derive from low grade DCIS, whereas high grade DCIS is the precursor of high grade (poorly differentiated, grade 3) invasive carcinomas [1], and this not surprisingly - suggests that LG DCIS and HG DCIS have different prognoses. For invasive carcinomas, the Nottingham grading scheme [2] has gained worldwide acceptance, and is generally recommended in guidelines [3-6]. This distinguishes between 3 histological grades with worsening prognosis. On the other hand, gene expression profiling studies have suggested a two-tiered prognostic separation, which lumps mostly histological grade 1 tumours and part of grade 2 tumours into a single group, the molecular (genomic) low grade category, and leaves the rest of histological grade 2 tumours and most grade 3 tumours for the molecular (genomic) high grade category [7]. This could mean that histological grade 2 tumours would reflect only our inability to classify these tumours as of better or worse prognosis on the basis of haematoxylin and eosin (HE) stained histological slides. Being a mixture of low and high genomic grade tumours, histological grade 2 carcinomas, as a group, obviously have intermediate prognosis between grade 1 and 3 tumours.

Similarly to invasive breast carcinoma, DCIS has also been found to be classifiable into two molecular grades with a split of intermediate histological grade DCIS cases into low and high molecular grades $[8,9]$. In keeping with the above notion, while the low-grade pathway and high grade pathway seem generally accepted [1], there has been no proposition to state that intermediate grade DCIS gives ground to grade 2 invasive carcinomas, although this may be true in a number of cases.

As DCIS, by definition, does not give rise to metastases, its treatment could be local alone. By removing / abolishing a precursor lesion, one can prevent the disease which develops from it. On the other hand, as DCIS is a non-obligate precursor, removing lesions that will not progress to invasive carcinoma constitutes overtreatment. The low grade pathway mentioned before is not only associated with a better prognosis, but also with a slower rate of progression [10] and recurrence [11-13], and also a continuous rate of recurrence [9]. Some DCIS never progress to invasive carcinoma. By now, clinical studies have formulated the aim of proving that observation of low risk / low grade DCIS can have identical outcomes than (is not inferior to) surgical removal \pm radiotherapy of these lesions [14-16]. The low risk DCIS trials (LORIS - LOw RISk dcis trial, LORD - LOw Risk Dcis trial and COMET Comparison of Operative to Monitoring and Endocrine Therapy) have well stated inclusion (and exclusion) criteria [17]. Basically, they recruit screen detected patients presenting with microcalcification alone and diagnosed with either low grade (LORD) or low grade and low end of intermediate grade non-high grade (LORIS, COMET) DCIS on the basis of (large gauge) needle biopsies providing generous sampling. These patients are randomized between observation (i.e. active surveillance) and conventional surgery with or without radiotherapy with the possible addition of endocrine therapy in COMET [14-18].

But what do we or others mean by different grades of DCIS?

\section{Grading DCIS - A Babelian Mixture of Languages}

DCIS is traditionally graded as low, intermediate and high grade, and this is the recommendation made by the last edition of the European Guidelines [3]. There are cases, which are textbook examples of low grade (Fig. 1a) and high grade (Fig. 1b) DCIS, and probably even unexperienced pathologist would also reach a good concordance in classifying them according to grade. On the other hand, there are cases which give more pain for those trying to grade them. This must be partially related to the lack of uniformity in the guidelines for grading the disease. Figure 2 highlights the features considered while classifying DCIS into one of the grades according to some guidelines in use, and it shows that these features are not fully identical (The aim of Fig. 2 is to give a visual impression; Supplementary Table 1 summarizes the wording for the interested [3-5, 18-25]). Nuclear size criteria are included in many of these schemes, but as Fig. 3 highlights it, there is ground to interpret the cases differently $[3-5,18$, 20-25].

A further source of confusion may stem from the terminology used. One of the first multinational European contemporary proposal for classification was the one by Holland et al., and this distinguished between well, intermediately and poorly differentiated DCIS [19]. As grade reflects differentiation in cancer, and invasive breast carcinomas of (histological) grade 1 are well differentiated, whereas those of (histological) grade 2 and 3 are moderately and poorly differentiated, respectively, it is tempting to equate the differentiation terminology with grade. But the generally accepted Nottingham grading system used for invasive breast carcinomas is a combined histological grade [2], in contrast to the nuclear grading system described by Black, which originally features a confusing (reverted) meaning of grades (grade 1 being the worst) [26]. The wellmoderately/intermediately-poorly differentiated terminology for DCIS is based on cytonuclear and architectural differentiation [19], and therefore does not merely reflect the nuclear grade often used for grading DCIS. When one uses the term grade with a meaning corresponding to a set of complex nuclear and structural criteria (Fig. 2), reproducibility may suffer from the lack of weighting between these criteria: e.g. when 
Fig. 1 Examples of obvious low (a) and high (b) grade DCIS.

Arrows point at single

erythrocytes $(\mathrm{RBC})$ in capillaries

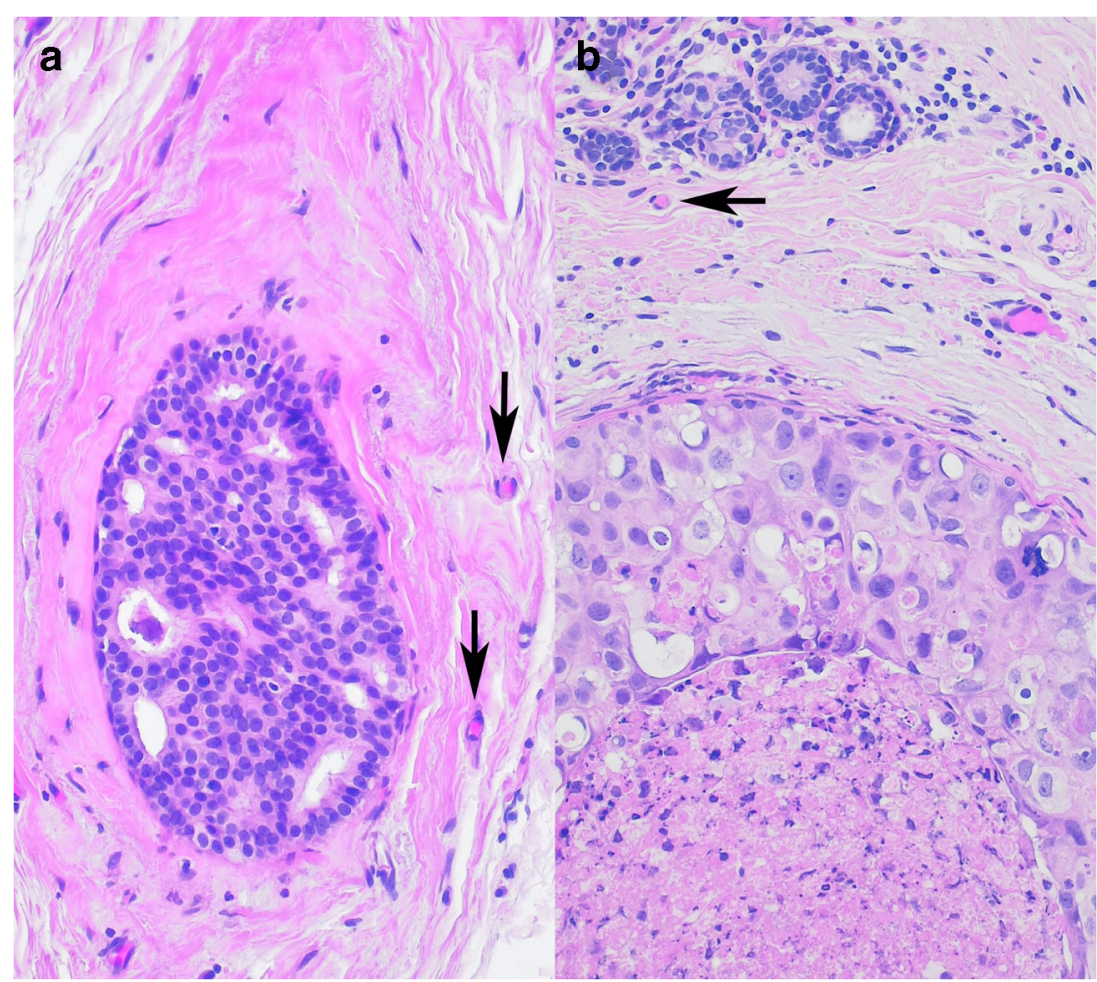

the nucleus is not large enough to qualify for high grade, but structural features are those often seen in poorly differentiated DCIS, e.g. the lack of cellular orientation is conspicuous, there are many mitoses, necrosis is present.

To add to this confusion, the low risk (for recurrence, for invasive recurrence, for upgrading between needle biopsy and surgical specimen, for death after progression) of low risk DCIS is not only related to nuclear grade / differentiation, but also to other features like size / extent, margin involvement or proximity, age, proliferation. This has given rise to formulate prognostic indices, scores or multifactorial classifications [9, 20, 27-29] and molecular approaches.

\section{Reproducibility of Classifying DCIS}

As assessed by statistical means, the previously introduced and currently used recommendations for grading DCIS are far from being perfectly reproducible among observers. Several studies have looked at the consistency of grading or prognostically classifying DCIS, and generally found that these DCIS classifications were moderately reproducible, while a few others suggested worse or somewhat better agreement (Supplementary Table 2 and Fig. 4 representing it)[6, 19, 20, 30-39]. This degree of interobserver variability is also reflected by a recent analysis of nearly 5000 DCIS diagnosed during a period of 4 years in the

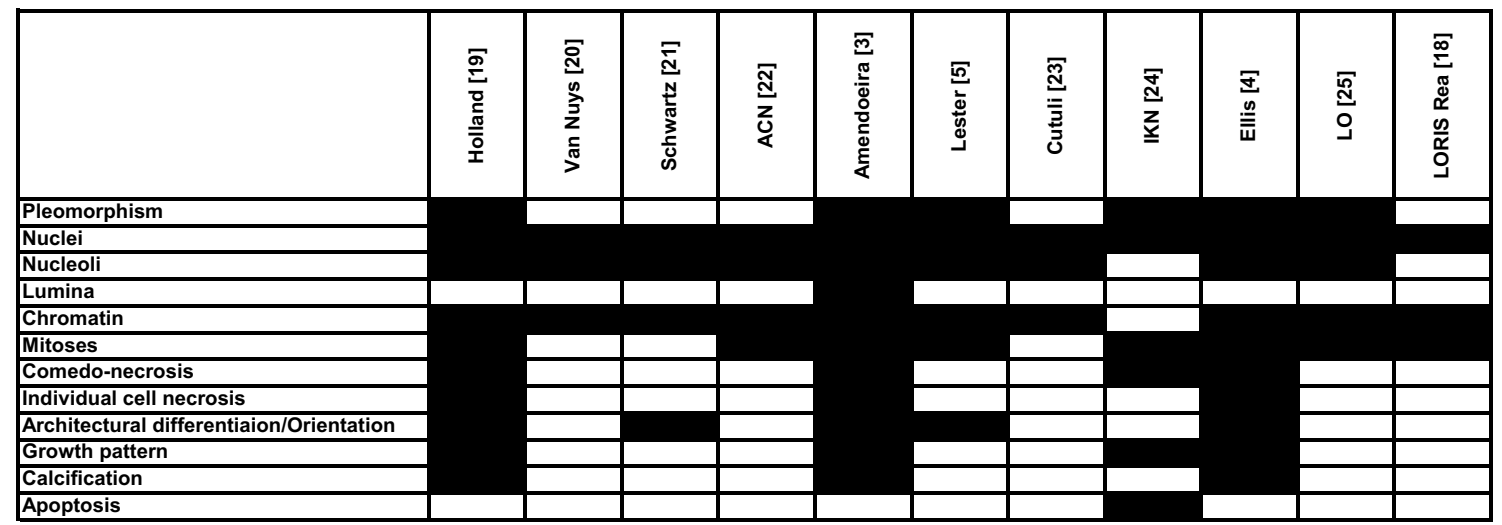

Fig. 2 Features considered for grading DCIS according to different recommendations. ACN: Australian Cancer Network; IKN: Integraal Kankercentrum Nederland; LO: Leitlinienprogramm-Onkologie [3-5, 18-25] 


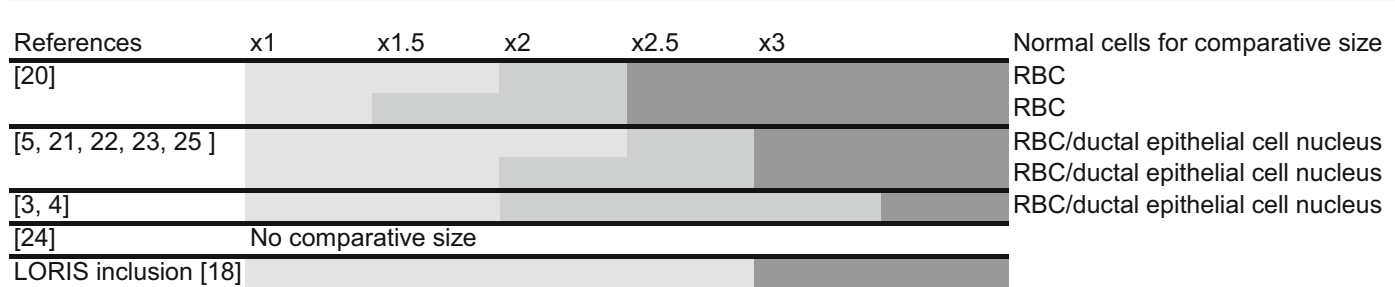

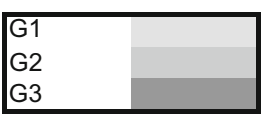

Fig. 3 Comparative nuclear size described in some publications concerning the grading of DCIS. RBC: red blood cell / erythrocyte [3-5, 18, 20-25]

Netherlands, and suggesting that the proportion of low grade DCIS varied between 6 and $24 \%$ by department. This is not so surprising as Fig. 4 reflects results gained with uniform classification criteria, whereas a questionnaire based assessment in the quoted Dutch study revealed a heterogeneity in the grading schemes used [40].

Although the values reflecting interobserver reproducibility for DCIS grading (Fig. 4) are not (much) worse than for many other features judged by microscopy (e.g. the grade of invasive breast carcinoma; the reporting of microinvasion in carcinoma in situ; the identification of lymphovascular invasion), they suggest that studies looking at the prognosis or prognostic markers of DCIS cannot ignore this degree of variability, and steps aiming at improving this are warranted.

As seen with other morphological features, a classification in a two-tiered system is always more consistent than one in a threetiered system, simply by the fact that by chance identical categorization is greater. This is also exemplified by the study of Van Bockstal et al. [38], who found that reproducibility is improved when 2 categories are used instead of 3 , but also highlighted that the distinction between high grade versus non-high grade was better (median Cohen's kappa value: 0.53) than the distinction between low grade versus non-low grade (median Cohen's kappa value: 0.39) (Fig. 4). This may be a worthwhile approach to improve reproducibility of the prognostic grouping of DCIS on morphological grounds, although as stated in the first section, the intermediate grade might reflect our less than perfect ability to distinguish between the good (low genomic grade, low risk) and the bad (high genomic grade, high risk).

\section{Further Inconsistencies}

Beside the determination of differentiation, i.e. grading, there are other inconsistencies in recommendations concerning the classification of DCIS. For some reasons, the 1997 consensus conference recommendations have included a comedo pattern among the traditionally recognized non-special types of DCIS, therefore making 5 major pattern categories: comedo, solid, cribriform, micropapillary, papillary [21]. Others recognize "comedo" only as a type of necrosis, which can occur with the solid, but also with other patterns of DCIS [4]. For some, necrosis worth to be mentioned is only the central comedo type necrosis [4, 20], and
Reference/Scheme Bethwaite [31]

Sneige [32]

Sloane [33]

Sloane [33]

Wells [34]

Douglas-Jones [35]

Gomes [36]

Gomes [36]

Schuh [37]

van Bockstal [38]

van Bockstal [38]

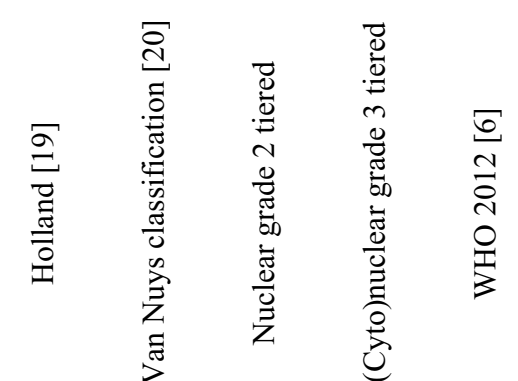

Fig. 4 Different agreement levels reached in reproducibility studies on DCIS grade [6, 19, 20, 31-39] 
punctate, focal necrosis needs no reporting, whereas the 1997 Philadelphia Consensus Conference recommendation, and national guidelines following these recommendations recognize non-comedo type (punctate) necrosis, too, and recommend reporting it separately $[21,23]$.

\section{Concluding Remarks}

The fact that DCIS classification is not uniform and harmonious is well recognized, and the need to establish a uniform classification system was formulated before. This is even more stressed, when studies try to prove that low grade or non-high grade (low risk) DCIS may not require anything else than careful follow-up. It is imperative to delineate what people should mean by low grade / low risk DCIS, in order to have a uniform interpretation not only of specific cases, but also of study results. This may have an impact on patient treatment or omission of treatment.

It might perhaps be wise to introduce a new, previously unused and uncompromised terminology as well, as disciples of former schools may understand the same term differently, as suggested by our Figs. 2 and 3. It seems that some existing national or regional guidelines use the same sources to be followed for grading DCIS, but obviously there are differences even between European countries and within counties. The running trials aiming at clarifying the outcome of low-risk DCIS without treatment also use somewhat different inclusion criteria [17].

There is a need to sort out the heterogeneity in terminology and the development of a common language that would mean the same thing to all those who communicate on it in order to avoid misclassification and the ensuing possibility of mistreatment simply arising from misunderstanding.

Acknowledgments This review was partially supported by the National Research, Development and Innovation Office grant GINOP-2.3.2-152016-00020.

Funding Open access funding provided by University of Szeged (SZTE) Open Access Fund; Grant number 4446. This work was partially supported by the National Research, Development and Innovation Office grant GINOP-2.3.2-15-2016-00020.

Compliance with Ethical Standards The authors have consulted the journal policy regarding compliance with ethical standards and state that accepted principles of ethical and professional conduct have been followed. The authors include information regarding sources of funding (previous section) and potential conflicts of interest (financial or non-financial) (next section). As no patients or patients' data are involved, ethical approval and informed consent are not applicable, similarly to animal welfare related issues.

Conflict of Interest The authors declare that they have no conflict of interest.
Open Access This article is distributed under the terms of the Creative Commons Attribution 4.0 International License (http:// creativecommons.org/licenses/by/4.0/), which permits unrestricted use, distribution, and reproduction in any medium, provided you give appropriate credit to the original author(s) and the source, provide a link to the Creative Commons license, and indicate if changes were made.

\section{References}

1. Wilkerson PM, Dedes KJ, Lopez-Garcia MA, Geyer FC, ReisFilho JS (2011) The molecular evolution of breast cancer precursors and risk indicators. In: Kahán Z, Tot T (eds) Breast cancer, a heterogeneous disease entity. The very early stages. Springer Science+ Business Media, Dordrecht, pp 89-117

2. Elston CW, Ellis IO, Pathological prognostic factors in breast cancer. I (1991) The value of histological grade in breast cancer: experience from a large study with long-term follow-up. Histopathology 19:403-410

3. Amendoeira I, Apostolikas N, Bellocq JP, Bianchi S, Boecker W, Borisch B, Bussolati G, Connolly CE, Cserni G, Decker T, Dervan P, Drijkoningen M, Ellis IO, Elston CW, Eusebi V, Faverly D, Heikkila P, Holland R, Kerner H, Kulka J, Jacquemier J, Lacerda M, Martinez-Penuela J, De Miguel C, Nordgren H, Peterse JL, Rank F, Regitnig P, Reiner A, Sapino A, Sigal-Zafrani B, Tanous AM, Thorstenson S, Zozaya E, Wells CA, EC Working Group on Breast Screening Pathology (2006) Quality assurance guidelines for pathology. In: Perry N, Broeders M, de Wolf C, Törnberg S, Holland R, von Karsa L (eds) European guidelines for quality assurance in breast cancer screening and diagnosis, 4th edn. European Comission, Luxemburg, pp 219-311

4. Ellis IO, Carder P, Hales S, Lee AHS, Pinder SE, Rakha E, Al-Sam S, Deb R, Hanby A, Liebmann R, Provenzano E, Rowlands D, Wells CA, Anderson N, Girling A, Ibrahim M, Mallon E, Quinn C (2016) Pathology reporting of breast disease in surgical excision specimens incorporating the dataset for histological reporting of breast cancer. The Royal College of Pathologists. https://www. rcpath.org/uploads/assets/uploaded/c5a73c7a-50a4-40778815c49abbcbc1f1.pdf. Accessed 13 May 2019

5. Lester SC, Bose S, Chen YY, Connolly JL, de Baca ME, Fitzgibbons PL, Hayes DF, Kleer C, O'Malley FP, Page DL, Smith BL, Tan LK, Weaver DL, Winer E (2009) Protocol for the examination of specimens from patients with ductal carcinoma in situ of the breast. Arch Pathol Lab Med 133:15-25

6. Schnitt SJ, Allred C, Britton P, Ellis IO, Lakhani SR, Morrow M, Palazzo J, Reynolds C, Rutgers E, Simpson J, van de Vijver MJ, Vincent-Salomon A (2012) Ductal carcinoma in situ. In: Lakhani SR, Ellis IO, Schnitt SJ, Tan PH, van de Vijver MJ (eds) WHO classification of tumours of the breast, 4th edn. International Agency for Research on Cancer, Lyon, pp 90-94

7. Sotiriou C, Wirapati P, Loi S, Harris A, Fox S, Smeds J, Nordgren H, Farmer P, Praz V, Haibe-Kains B, Desmedt C, Larsimont D, Cardoso F, Peterse H, Nuyten D, Buyse M, Van de Vijver MJ, Bergh J, Piccart M, Delorenzi M (2006) Gene expression profiling in breast cancer: understanding the molecular basis of histologic grade to improve prognosis. J Natl Cancer Inst 98:262-272

8. Hannemann J, Velds A, Halfwerk JB, Kreike B, Peterse JL, van de Vijver MJ (2006) Classification of ductal carcinoma in situ by gene expression profiling. Breast Cancer Res 8:61

9. Balleine RL, Webster LR, Davis S, Salisbury EL, Palazzo JP, Schwartz GF, Cornfield DB, Walker RL, Byth K, Clarke CL, Meltzer PS (2008) Molecular grading of ductal carcinoma in situ of the breast. Clin Cancer Res 14:8244-8252 
10. Sanders ME, Schuyler PA, Simpson JF, Page DL, Dupont WD (2015) Continued observation of the natural history of low-grade ductal carcinoma in situ reaffirms proclivity for local recurrence even after more than 30 years of follow-up. Mod Pathol 28:662669

11. Maxwell AJ, Clements K, Hilton B, Dodwell DJ, Evans A, Kearins O, Pinder SE, Thomas J, Wallis MG, Thompson AM (2018) Risk factors for the development of invasive cancer in unresected ductal carcinoma in situ. Eur J Surg Oncol 44:429-435

12. Cserni G (2002) Tumour histological grade may progress between primary and recurrent invasive mammary carcinoma. J Clin Pathol 55:293-297

13. Wang SY, Shamliyan T, Virnig BA, Kane R (2011) Tumor characteristics as predictors of local recurrence after treatment of ductal carcinoma in situ: a meta-analysis. Breast Cancer Res Treat 127:114

14. Elshof LE, Tryfonidis K, Slaets L, van Leeuwen-Stok AE, Skinner VP, Dif N, Pijnappel RM, Bijker N, Rutgers EJ, Wesseling J (2015) Feasibility of a prospective, randomised, open-label, international multicentre, phase III, non-inferiority trial to assess the safety of active surveillance for low risk ductal carcinoma in situ - the LORD study. Eur J Cancer 51:1497-1510

15. Francis A, Thomas J, Fallowfield L, Wallis M, Bartlett JM, Brookes C, Roberts T, Pirrie S, Gaunt C, Young J, Billingham L, Dodwell D, Hanby A, Pinder SE, Evans A, Reed M, Jenkins V, Matthews L, Wilcox M, Fairbrother P, Bowden S, Rea D (2015) Addressing overtreatment of screen detected DCIS; the LORIS trial. Eur J Cancer 51:2296-2303

16. ClinicalTrials.gov. https://clinicaltrials.gov/ct2/show/ NCT02926911. Accessed 13 May 2019

17. Toss M, Miligy I, Thompson AM, Khout H, Green AR, Ellis IO, Rakha EA (2017) Current trials to reduce surgical intervention in ductal carcinoma in situ of the breast: critical review. Breast 35: $151-156$

18. Rea D, Francis A, Wallis M, Thomas J, Bartlett J, Bowden S, Dodwell D, Fallowfield L, Gaunt C, Hanby A, Jenkins V, Matthews L, Pinder S, Pirrie S, Reed M, Wilcox M, Roberts T, Kirwan C, Brookes C, Fairbrother P, Billingham L, Evans A, Young J (2017) Confusion over differences in registration and randomization criteria for the LORIS (low-risk DCIS) trial. Ann Surg Oncol 24(Suppl 3):566-567

19. Holland R, Peterse JL, Millis RR, Eusebi V, Faverly D, van de Vijver MJ, Zafrani B (1994) Ductal carcinoma in situ: A proposal for a new classification. Semin Diagn Pathol 11:167-180

20. Silverstein MJ, Lagios MD, Craig PH, Waisman JR, Lewinsky BS, Colburn WJ, Poller DN (1996) A prognostic index for ductal carcinoma in situ of the breast. Cancer 77:2267-2274

21. Consensus Conference Committee (1998) Consensus Conference on the classification of ductal carcinoma in situ. Cancer 1;82:22932295

22. National Breast and Ovarian Cancer Centre and Australian Cancer Network (2008) The pathology reporting of breast cancer. A guide for pathologists, surgeons, radiologists and oncologists, 3rd edn. National Breast and Ovarian Cancer Centre, Surry Hills, NSW. https://www.cancer.org.au/content/pdf/HealthProfessionals/ ClinicalGuidelines/Pathology_reporting_breastcancer_3rdEd2008. pdf. Accessed 13 May 2019
23. Cutuli B, Arnould L, Barreau B, Bellocq JP, Bonnier P, Fignon A, Fondrinier E, Fourquet A, Lemanski C, Lesur A, Sigal-Zafrani B, Tunon de Lara C (2009) Recommandations professionnelles Cancer du Sein in situ. Institut National du Cancer, BoulogneBillancourt. https://www.ecancer.fr/content/download/95918/ 1021188/file/RECOSIS10.pdf. Accessed 13 May 2019

24. Integraal Kankercentrum Nederland (2012) Breast cancer: Dutch guidelines, version 2.0; NABON 2012. Oncoline. https://www. oncoline.nl/uploaded/docs/mammacarcinoom/Dutch\%20Breast\% 20Cancer\%20Guideline\%202012.pdf. Accessed 13 May 2019

25. Leitlinienprogramm Onkologie (2018) Interdisziplinäre S3Leitlinie für die Früherkennung, Diagnostik, Therapie und Nachsorge des Mammakarzinoms. Langversion 4.1. https://www. leitlinienprogramm-onkologie.de/leitlinien/mammakarzinom/. Accessed 13 May 2019

26. Fisher ER, Gregorio RM, Fisher B, Redmond C, Vellios F, Sommers SC (1975) The Pathology of invasive breast cancer. A Syllabus derived from findings of the National Surgical Adjuvant Breast Project (Protocol No. 4). Cancer 36:1-85

27. Silverstein MJ (2003) The University of Southern California/Van Nuys prognostic index for ductal carcinoma in situ of the breast. Am J Surg 186:337-343

28. Rudloff U, Brogi E, Reiner AS, Goldberg JI, Brockway JP, Wynveen CA, McCormick B, Patil S, Van Zee KJ (2010) The influence of margin width and volume of disease near margin on benefit of radiation therapy for women with DCIS treated with breast-conserving therapy. Ann Surg 251(4):583-591

29. Sagara Y, Freedman RA, Vaz-Luis I, Mallory MA, Wong SM, Aydogan F, DeSantis S, Barry WT, Golshan M (2016) Patient Prognostic Score and Associations With Survival Improvement Offered by Radiotherapy After Breast-Conserving Surgery for Ductal Carcinoma In Situ: A Population-Based Longitudinal Cohort Study. J Clin Oncol 10;34(11):1190-1196

30. Scott MA, Lagios MD, Axelsson K, Rogers LW, Anderson TJ, Page DL (1997) Ductal carcinoma in situ of the breast: reproducibility of histological subtype analysis. Hum Pathol 28:967-973

31. Bethwaite P, Smith N, Delahunt B, Kenwright D (1998) Reproducibility of new classification schemes for the pathology of ductal carcinoma in situ of the breast. J Clin Pathol 51:450-454

32. Sneige N, Lagios MD, Schwarting R, Colburn W, Atkinson E, Weber D, Sahin A, Kemp B, Hoque A, Risin S, Sabichi A, Boone C, Dhingra K, Kelloff G, Lippman S (1999) Interobserver reproducibility of the Lagios nuclear grading system for ductal carcinoma in situ. Hum Pathol 30(3):257-262

33. Sloane JP, Amendoeira I, Apostolikas N, Bellocq JP, Bianchi S, Boecker W, Bussolati G, Coleman D, Connolly CE, Eusebi V, De Miguel C, Dervan P, Drijkoningen R, Elston CW, Faverly D, Gad A, Jacquemier J, Lacerda M, Martinez-Penuela J, Munt C, Peterse JL, Rank F, Sylvan M, Tsakraklides V, Zafrani B (1999) Consistency achieved by 23 European pathologists in categorizing ductal carcinoma in situ of the breast using five classifications. European Commission Working Group on Breast Screening Pathology. Hum Pathol 29(10):1056-1062

34. Wells WA, Carney PA, Eliassen MS, Grove MR, Tosteson AN (2000) Pathologists' agreement with experts and reproducibility of breast ductal carcinoma-in-situ classification schemes. Am J Surg Pathol 24(5):651-659 
35. Douglas-Jones AG, Morgan JM, Appleton MAC, Attanoos RL, Caslin A, Champ CS, Cotter M, Dallimore NS, Dawson A, Fortt RW, Griffiths AP,Hughes M, Kitching PA, O’Brien C, Rashid AM, Stock D, Verghese A, Williams DW, Williams NW, Williams S (2000) Consistency in the observation of features used to classify duct carcinoma in situ (DCIS) of the breast. J Clin Pathol 53:596602

36. Gomes DS, Porto SS, Balabram D, Gobbi H (2014) Inter-observer variability between general pathologists and a specialist in breast pathology in the diagnosis of lobular neoplasia, columnar cell lesions, atypical ductal hyperplasia and ductal carcinoma in situ of the breast. Diagn Pathol 19;9:121

37. Schuh F, Biazus JV, Resetkova E, Benfica CZ, de Freitas Ventura A, Uchoa D, Graudenz M, Edelweiss MIA (2015) Histopathological grading of breast ductal carcinoma in situ: validation of a webbased survey through intra-observer reproducibility analysis. Diagn Pathol 10:93
38. Van Bockstal M, Baldewijns M, Colpaert C, Dano H, Floris G, Galant C, Lambein K, Peeters D, Van Renterghem S, Van Rompuy AS, Verbeke S, Verschuere S, Van Dorpe J (2018) Dichotomous histopathological assessment of ductal carcinoma in situ of the breast results in substantial interobserver concordance. Histopathology 73(6):923-932

39. Landis JR, Koch GG (1977) The measurement of observer agreement for categorical data. Biometrics 33(1):159-174

40. Van Dooijeweert C, van Diest PJ, Willems SM, Kuijpers CCH, Deckers IAG (2019) Significant inter- and intra-laboratory variation in grading of ductal carcinoma in situ of the breast: a nationwide study of 4901 patients in the Netherlands. Breast Cancer Res Treat 174(2):479-488

Publisher's Note Springer Nature remains neutral with regard to jurisdictional claims in published maps and institutional affiliations. 